\title{
TNF Neutralization Results in the Delay of Transplantable Tumor Growth and Reduced MDSC Accumulation
}

\begin{abstract}
Kamar-Sulu N. Atretkhany, ${ }^{1,2}$, Maxim A. Nosenko, ${ }^{1,2,3}$, Violetta S. Gogoleva ${ }^{1,2}$, Ruslan V. Zvartsev' ${ }^{1}$ Zhihai Qin ${ }^{4}$, Sergei A. Nedospasov1,2,3 and Marina S. Drutskaya ${ }^{1 *}$

${ }^{1}$ Engelhardt Institute of Molecular Biology, Russian Academy of Sciences, Moscow, Russia, ${ }^{2}$ Immunology Department, Faculty of Biology, Beloszersky Institue of Physico-Chemical Biology, Lomonosov Moscow State University, Moscow, Russia, ${ }^{3}$ German Rheumatology Research Center (DRFZ), Berlin, Germany, ${ }^{4}$ Institute of Biophysics, Chinese Academy of Sciences, Beijing, China
\end{abstract}

Myeloid-derived suppressor cells (MDSCs) represent a heterogeneous population of immature myeloid cells (IMCs) that, under normal conditions, may differentiate into mature macrophages, granulocytes, and dendritic cells. However, under pathological conditions associated with inflammation, cancer, or infection, such differentiation is inhibited leading to IMC expansion. Under the influence of inflammatory cytokines, these cells become MDSCs, acquire immunosuppressive phenotype, and accumulate in the affected tissue, as well as in the periphery. Immune suppressive activity of MDSCs is partly due to upregulation of arginase 1, inducible nitric oxide synthase, and anti-inflammatory cytokines, such as IL-10 and TGF- $\beta$. These suppressive factors can enhance tumor growth by repressing T-cell-mediated anti-tumor responses. TNF is a critical factor for the induction, expansion, and suppressive activity of MDSCs. In this study, we evaluated the effects of systemic TNF ablation on tumor-induced expansion of MDSCs in vivo using TNF humanized (hTNF KI) mice. Both etanercept and infliximab treatments resulted in a delayed growth of MCA 205 fibrosarcoma in hTNF KI mice, significantly reduced tumor volume, and also resulted in less accumulated MDSCs in the blood 3 weeks after tumor cell inoculation. Thus, our study uncovers anti-tumor effects of systemic TNF ablation in vivo.

Keywords: MDSC, transplantable tumor model, anti-cytokine therapy, IL-6, TNF, pro-inflammatory cytokines, MCA 205 fibrosarcoma

\section{INTRODUCTION}

Myeloid-derived suppressor cells (MDSCs) constitute a heterogeneous population of immature myeloid cells (IMCs) that instead of undergoing terminal differentiation start to expand under the influence of inflammation, cancer, or infection (1). These cells are characterized by co-expression of CD11b and Gr-1 and can be subdivided into two populations: granulocytic CD $11 b^{+} \mathrm{Ly}_{6} \mathrm{G}^{+} \mathrm{Ly} 6 \mathrm{C}^{\text {low }}$ and monocytic CD11 $\mathrm{b}^{+} \mathrm{Ly} 6 \mathrm{G}^{-} \mathrm{Ly} 6 \mathrm{C}^{\mathrm{hi}}$ cells (2). Initially, their accumulation was detected in cancer patients, but later an expansion of such heterogeneous population of myeloid cells with suppressive functions was also reported in several experimental carcinogenesis models in mice (3-8). It is believed 
that tumor microenvironment releases various factors, such as GM-CSF, M-CSF, and VEGF, which may stimulate myelopoiesis, as well as the production of pro-inflammatory cytokines, such as IL-6, TNF, and IL-1 $\beta$, and anti-microbial peptides S100A8 and S100A9 (9). These factors may promote inflammation and induce activation and expansion of MDSCs via transcription programs controlled by STAT1, STAT3, and NFkB transcription factors (10-12). Suppressive activity of MDSCs is associated with upregulation of arginase 1 (Arg1), inducible nitric oxide synthase (iNOS), reactive oxygen species (ROS), and anti-inflammatory cytokines, such as IL-10 and TGF- $\beta$ (9, 13-15). These suppressive factors can enhance tumor growth by repressing $\mathrm{T}$-cell proliferation as well as T-cell- and NK-cell-mediated anti-tumor responses (16-19). Furthermore, IL-10 and TGF- $\beta$ production by MDSCs may lead to the induction of T-regulatory cells and M2 macrophages with suppressive capacity (20-22). Additionally, MDSCs can attract other myeloid cells, such as neutrophils and macrophages, which further contribute to the inflammatory processes in tumor microenvironment (23).

TNF is a multifunctional cytokine involved in host defense, immune regulation, cell survival, lymphoid tissue organogenesis, and inflammation (24). TNF was initially described due to its potent anti-tumor effects against Meth A sarcoma and other transplantable tumors in mice (25). However, cancer therapy with systemically administered recombinant human TNF is associated with severe side effects due to TNF-mediated inflammation and toxicity (26). Ironically, given its name - tumor necrosis factor, it was later found that TNF may play a pro-tumorigenic role by enhancing chronic inflammation (27-30). These opposing functions of TNF in experimental carcinogenesis models can be attributed to complex signaling networks involving a constellation of TNF-producing cells and two different TNF receptors. TNF exists both in soluble and membrane-bound forms. In addition, a soluble form of lymphotoxin ( $\mathrm{sLTa}$ and $\mathrm{LT} \alpha_{3}$ ), a molecule closely related to TNF, can also signal through the same receptors (31). It was recently demonstrated in a transplantable tumor model that TNF-TNFRII axis may control the survival of MDSCs through upregulation of cellular FLICE-inhibitory protein (c-FLIP), leading to the inhibition of caspase-8 activity (32). Moreover, membrane-associated form of TNF (tmTNF) appears more potent than soluble TNF (sTNF) for MDSC activation (33). It was also reported that TNFRII is crucial for the suppressive activity of MDSCs, since myeloid cells without TNFRII failed to produce IL-6 and NO (34). Finally, in chronic inflammation experiments, it was found that TNF inhibits differentiation of myeloid cells and increases suppressive capacity of MDSCs. MDSCs from TNFdeficient mice failed to suppress T-cell proliferation, produced lower levels of iNOS, S100A8, S100A9, and RAGE (35).

Tumor microenvironment is orchestrated by a complex network of cells of both innate and adaptive immunity, which may contribute to the tumor progression, instead of inducing antitumor immune responses (36). MDSCs represent an important component of tumor microenvironment (23), which by activating different signaling pathways may induce survival and proliferation of tumor cells, suppress T-cell- and NK-cell-mediated anti-tumor immune responses, and promote angiogenesis and metastasis (9). Recent experimental data suggested that pro-inflammatory cytokines, such as TNF and IL-6, are necessary for the induction, expansion, and suppressive activity of MDSCs $(33,35,37,38)$. Therefore, we considered to address the impact of anti-cytokine therapy on tumor development and MDSC accumulation in a transplantable tumor model in mice. Pharmacological blockers of TNF and IL-6 are widely used in the clinic for treatment of various autoimmune disorders (39). Whether such long-term treatment may promote neoplasia in patients or, on the contrary, provide additional protection from emerging tumors is of high clinical relevance (40). In this study, we employed a unique experimental model to study the effects of TNF neutralization on tumor-induced expansion of MDSCs in vivo. Using pharmacological inhibition of human TNF in humanized mice (hTNF $\mathrm{KI}$ ) with either etanercept or infliximab, we demonstrated that in mice transplanted with MCA 205 fibrosarcoma, MDSC accumulation and tumor growth were significantly diminished. Our study provides another example of pro-tumorigenic activity of endogenous TNF that involves MDSCs and may be useful for future validation of cell-type-specific anti-cytokine therapy, targeting TNF on myeloid cells (41).

\section{MATERIALS AND METHODS}

\section{Mice}

Humanized TNF KI mice on $\mathrm{C} 57 \mathrm{Bl} / 6$ background were recently described $(41,42)$. C57Bl/6 mice and hTNF KI mice were bred at Animal Breeding Facility of Shemyakin and Ovchinnikov Institute of Bioorganic Chemistry, Puschino, Moscow Region, Russia, housed under specific pathogen-free conditions on $12 \mathrm{~h}$ light/dark cycle at room temperature. For tumor injections, age- and sex-matched $\mathrm{C} 57 \mathrm{Bl} / 6$ and hTNF KI mice were used at the age of $8-10$ weeks. All manipulations with animals were carried out in accordance with recommendations in the Guide for the Care and Use of Laboratory Animals (NRC 2011), the European Convention for the protection of vertebrate animals used for experimental and other scientific purposes, Council of Europe (ETS 123), and "The Guidelines for Manipulations with Experimental Animals" (the decree of the Presidium of the Russian Academy of Sciences of April 02, 1980, no. 12000-496). All animal procedures were approved by Scientific Council of the Engelhardt Institute of Molecular Biology.

\section{Tumor Cell Lines}

MCA 205 fibrosarcoma and EL4 T-cell lymphoma were cultured in RPMI 1640 medium supplemented with 10\% FBS, L-glutamine (2 $\mathrm{mM}), 100 \mathrm{U} / \mathrm{ml}$ penicillin, and $100 \mu \mathrm{g} / \mathrm{ml}$ streptomycin in the T75 flasks. Following four to six passages, tumor cells were harvested, washed in PBS, and injected subcutaneously into the abdomen region of mice in the amount of $1 \times 10^{6}$ cells in $200 \mu \mathrm{l}$. Tumor growth was monitored every $2-5$ days, and tumor volume was calculated as $(1 \times \mathrm{w} \times \mathrm{h})$ in cubic millimeter.

\section{TNF Blockers}

Etanercept (Pfizer Ireland Pharmaceuticals, Ireland, J17413) and infliximab (Schering-Plough, Ireland, 3RMKA86001) were used to neutralize TNF. Mice were injected with $10 \mu \mathrm{g} / \mathrm{g}$ of etanercept 
or infliximab every 3 days. Control mice received PBS. Tumor cells were injected 1 week after the first injection of TNF inhibitors.

\section{Flow Cytometry Analysis}

Single cell suspensions prepared from blood, spleen, and lymph nodes were stained with epitope-specific antibodies (eBioscience, Inc., San Diego, CA, USA): FITC-labeled Gr-1 (RB6-8C5), PE-labeled F4/80 (BM8), Pacific Blue-labeled B220 (RA3-6B2), Pe-Cy7-labeled Ly6C (HK 1.4), APC-labeled CD11b (M1/70), PerCP-Cy5.5-labeled CD45 (30-F11), and APC-Cy7-labeled viability dye. For blocking unspecific binding, anti-Fc gamma receptor antibodies (2.4G2) were used. For $\mathrm{NO}$ and ROS detection, carboxy- $\mathrm{H}_{2}$ DCFDA (Thermo Fisher Scientific) and DAF-FM diacetate (Thermo Fisher Scientific) were used, respectively, each at a final concentration of $1 \mu \mathrm{M}$. Data were acquired with FACSCanto II Cytometer (BD Biosciences) and analyzed with FlowJo software. Gating strategies are summarized in the supplementary figures for MDSCs in the blood (Figure S1A in Supplementary Material), MDSCs in the spleen and the lymph nodes (Figure S1B in Supplementary Material), T-cell proliferation assay (Figure S2A in Supplementary Material), and NO and ROS in the blood (Figure S2C in Supplementary Material).

\section{Real-time Quantitative RT-PCR Analysis}

Total RNA was isolated using the TRIzol Reagent (Invitrogen, Carlsbad, CA, USA), according to the manufacturer's protocol. Reverse transcription was performed using $1 \mu \mathrm{g}$ total RNA and oligo $(\mathrm{dT})_{18}$ primers with RevertAid first strand cDNA synthesis kit (Thermo Scientific, USA), according to the manufacturer's protocol. Real-time quantitative PCR was performed using qPCRmix-HS SYBR kit (Evrogen, Moscow, Russia) on the Applied Biosystems 7500 Real-Time PCR System (Applied Biosystems, Foster City, CA, USA). The following primers were used: Actb, F: 5'-GACCTCTATGCCAACACAGT, R: 5'-AGAAAGGGTGTA AAACGCAG; S100A9, F: 5'-TTAGCCTTGAAGAGCAAG AA GATGG, R: 5'-AGCTCAGCTGATTGTCCTGGT; Adam17, F: 5'-GGCCGG AAACGAGTTAAGCC, R: 5' -AGCTTCTCAAGT CGCGGATG; Nos2, F: 5'-GTCA ACTGCAAGAGAACGGAGA, R: 5' -TCTGTGCTGTCCCAGTGAGG; Bcl2ll, F: 5' -TGGAGTAAA CTGGGGTCGCA, R:5' -TCCACAAAAGTGTCCCAGCC; Arg1, F: 5'-CTCTGGGAATCTGCATGGGC, R: 5'-GGCCTTTTCTT CCTTCCCAGC; $T g f b 1$, F: 5'-TGCTGACCCCCACTGATACG, R: 5'-GTTTGGGGCTGATCCCGTTG; S100a8, F: 5'-CTTCAAG ACATCGTTTGAAAGG, R: 5'-ATTCTTGTAGAGGGCATGGT; Il10, F: 5'-GACAATAACTGCACCCACTTCC, R: 5' -AACCCAA GTAACCCTTAAAGTCC; and Il6, F: 5'-GTGGAAATGAGA AAAGAGTTGTGC, R: 5'-GGAGAGCATTGGAAATTGGGGT. Amplifications were performed using the following program: preheating stage at $95^{\circ} \mathrm{C}$ for $10 \mathrm{~min}, 40$ cycles at $95^{\circ} \mathrm{C}$ for $15 \mathrm{~s}$, annealing at $61^{\circ} \mathrm{C}$ for $30 \mathrm{~s}$, and extension at $72^{\circ} \mathrm{C}$ for $20 \mathrm{~s}$. Relative expression of target genes was determined according to $\Delta \Delta \mathrm{Ct}$ with normalization to $A c t b$ expression.

\section{T-Cell Proliferation Assay}

T-cells were isolated from spleens of naive mice using CD4 (L3T4) MicroBeads, according to the manufacturer's protocol (Miltenyi Biotec, Germany). T-cells were labeled with $5 \mathrm{mM}$
CFSE (Molecular Probes, USA) for $15 \mathrm{~min}$ at $37^{\circ} \mathrm{C}$, washed three times with cold RPMI, and diluted in 96-well roundbottom plates at concentration $4 \times 10^{5}$ cells in RPMI 1640 medium supplemented with $10 \% \mathrm{FBS}$, L-glutamine (2 mM), $100 \mathrm{U} / \mathrm{ml}$ penicillin, $100 \mu \mathrm{g} / \mathrm{ml}$ streptomycin, $10 \mathrm{mM}$ Hepes, $50 \mu \mathrm{M}$ b-ME, MEM (Thermo Fisher Scientific, 11130-051), and sodium pyruvate $(1 \mathrm{mM})$ in each well. These cells were cocultured with $2 \times 10^{6}$ purified splenic MDSCs from tumorbearing mice undergoing etanercept, infliximab, or PBS treatment. $\mathrm{CD} 11 \mathrm{~b}^{+} \mathrm{Gr}-1^{+}$cells were purified from the spleens of tumor-bearing mice using MDSC isolation kit, according to the manufacturer's protocol (Miltenyi Biotec, Germany). For stimulation of T-cell proliferation, we used anti-CD3 (clone 145-2C11) and anti-CD28 (clone 37.51) antibodies in final concentrations of $1 \mu \mathrm{g} / \mathrm{ml}$ and $6 \mathrm{ng} / \mathrm{ml}$, respectively. After $72 \mathrm{~h}$, cells were collected and analyzed by flow cytometry (Figure S2A in Supplementary Material).

\section{Statistical Analysis}

Statistical analysis was performed using GraphPad Prism software (version 6, San Diego, CA, USA). Two-tailed unpaired Student's $t$-test was used for comparison of two independent data samples and determination of the degree of reliability. The data were obtained in at least three independent experiments and presented as the mean \pm SD. $P$ values $<0.05$ were considered to indicate statistical significance.

\section{RESULTS}

\section{Systemic TNF Ablation with Etanercept Efficiently Reduces MCA 205 Tumor Growth and MDSC Accumulation in C57BI/6 Mice}

TNF is important for MDSC development, in turn, MDSCs play a crucial role in tumor progression $(9,35)$. Genetic studies suggested that TNF may play a pro-tumorigenic role in skin carcinogenesis model (27). Thus, we hypothesized that prolonged in vivo blockade of TNF with pharmacological agents may result in anti-tumor effects. To test this hypothesis, we evaluated the ability of clinically used TNF blockers to prevent transplantable tumor growth in mice. Our initial experiments were carried out in $\mathrm{C} 57 \mathrm{Bl} / 6$ mice using etanercept, a soluble fusion protein of human p75 TNF receptor and Fc portion of IgG1 antibody, as an inhibitor of murine TNF, because it is the only clinically available blocker that binds to murine TNF (43). We have chosen MCA fibrosarcoma cell line, since a potent anti-tumor effect of TNF in vivo was originally discovered on methyl-cholantrene-induced tumors (25). Specifically, we used transplantable tumor cell line, MCA205 fibrosarcoma, injected into C57Bl/6 mice, because the resulting tumors are known to be dependent on MDSC accumulation (32). As a control reagent in this first set of experiments, we used infliximab, a chimeric monoclonal antibody against human TNF, which does not bind murine TNF but has the same Fcy-domain as etanercept (44). The scheme of the experiment is shown in Figure 1. We first examined the growth kinetics of MCA 205 fibrosarcoma (Figure 2A) in C57Bl/6 recipients. Mice 


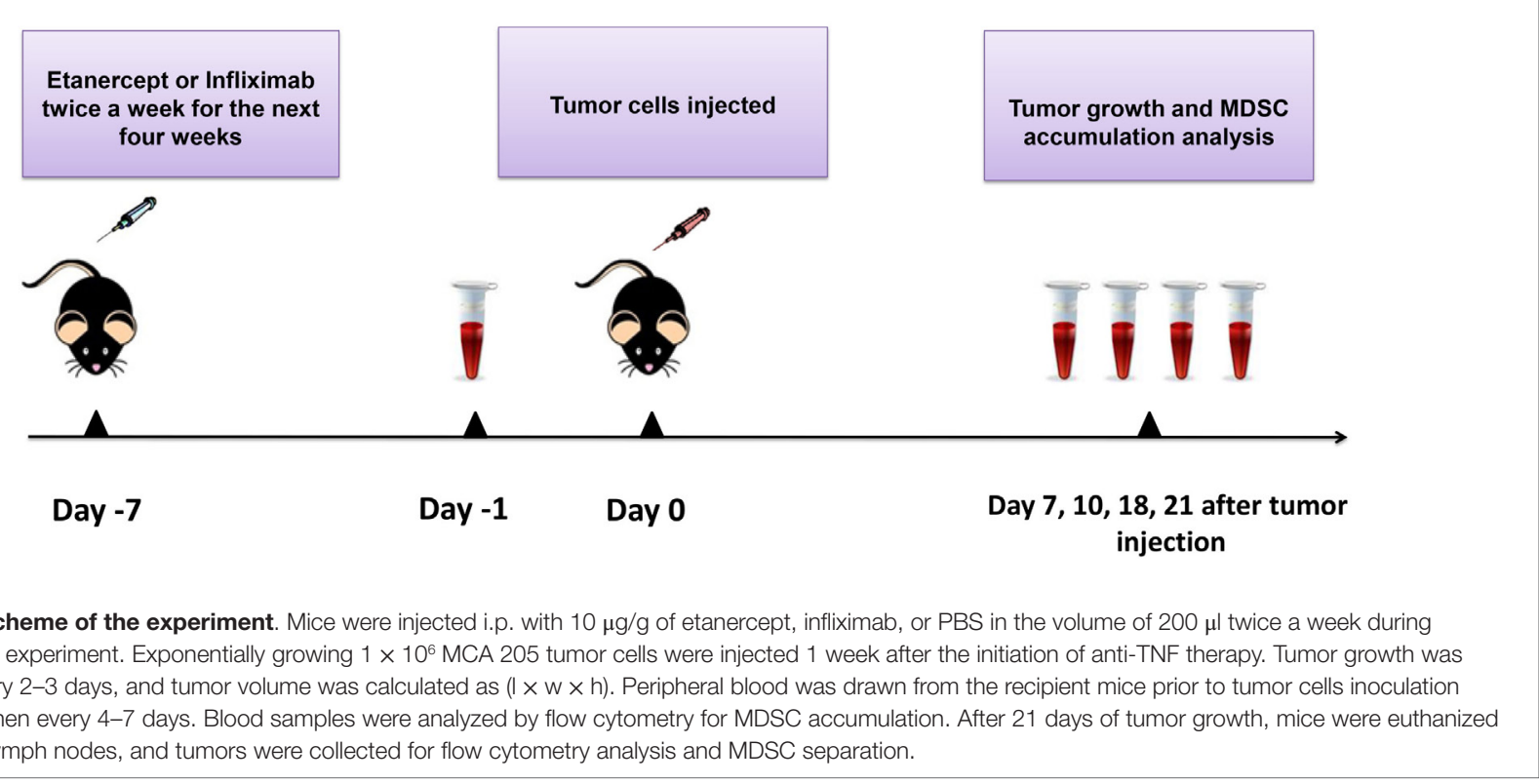

FIGURE 1 | Scheme of the experiment. Mice were injected i.p. with $10 \mu \mathrm{g} / \mathrm{g}$ of etanercept, infliximab, or PBS in the volume of $200 \mu \mathrm{l}$ twice a week during 4 weeks of the experiment. Exponentially growing $1 \times 10^{6}$ MCA 205 tumor cells were injected 1 week after the initiation of anti-TNF therapy. Tumor growth was monitored every 2-3 days, and tumor volume was calculated as $(I \times w \times h)$. Peripheral blood was drawn from the recipient mice prior to tumor cells inoculation (day -1 ) and then every 4-7 days. Blood samples were analyzed by flow cytometry for MDSC accumulation. After 21 days of tumor growth, mice were euthanized and spleens, lymph nodes, and tumors were collected for flow cytometry analysis and MDSC separation.
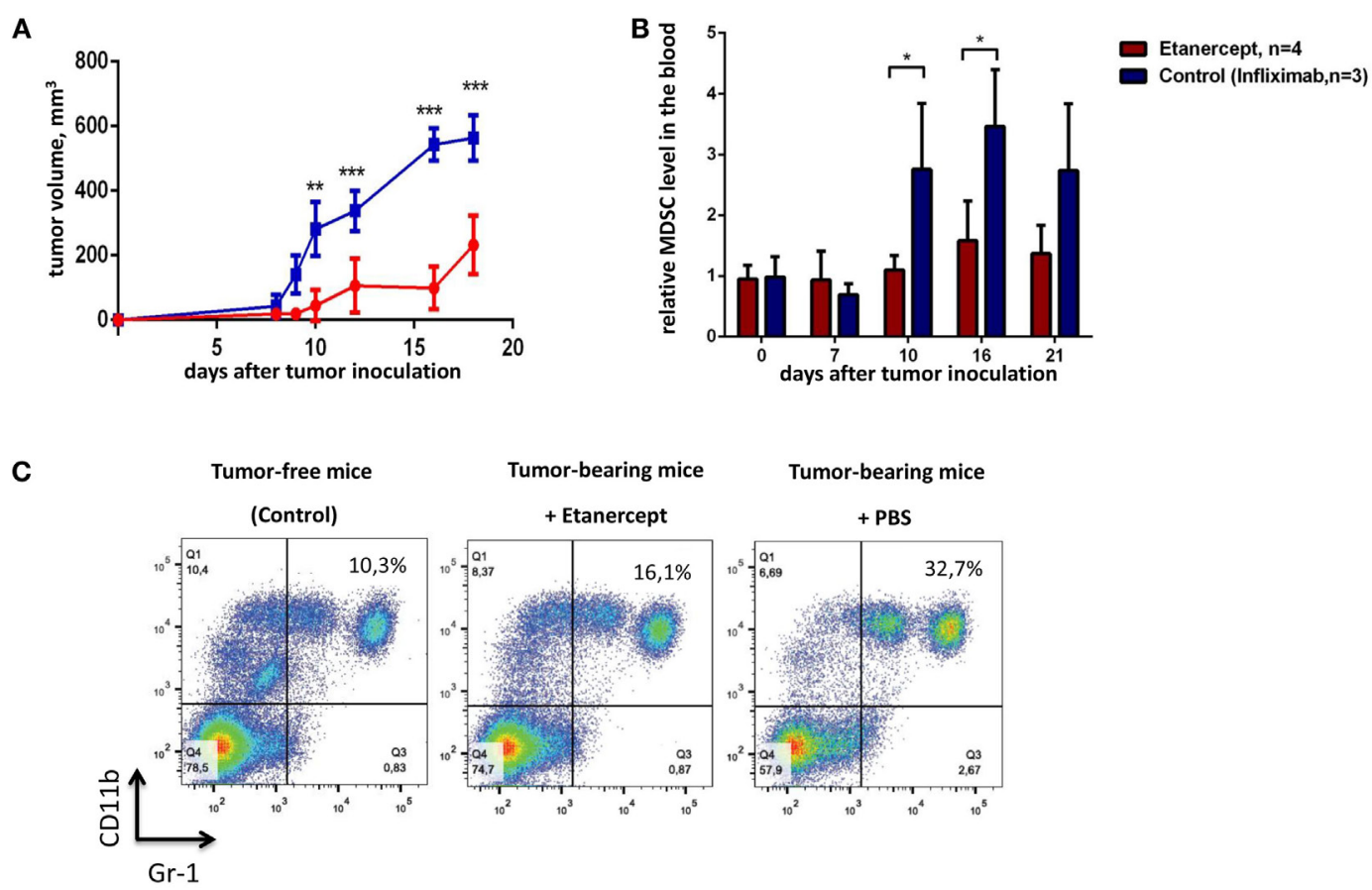

FIGURE 2 | Etanercept efficiently reduces transplantable tumor growth and MDSC accumulation in C57BI/6 mice. (A) Tumor growth in control mice (blue) and mice undergoing treatment with etanercept (red). Each line represents the growth curve of mean tumor volume \pm SD. (B) MDSC accumulation in the blood. Each bar represents mean relative MDSC level in the blood of tumor-bearing mice normalized to tumor-free mice \pm SD. (C) Representative dot plots for MDSC staining in the blood from mice without tumors (left), etanercept (middle), or PBS-treated (right) tumor-bearing mice on day 16 after tumor cells inoculation. Cells were first gated as VD-CD45+, and then CD11 b+Gr-1+ cells were defined as MDSCs (with Gr-1 antibody clone RB6-8C5 recognizing both Ly6G and Ly6C epitopes). Data are representative of two independent experiments with three to five mice per each group. ${ }^{*} p<0.5,{ }^{* *} p<0.01$, and ${ }^{* * *} p<0.001$.

treated with infliximab or PBS rapidly developed tumors with the similar kinetics (only infliximab group is shown as a control on Figure 2). Importantly, mice injected with etanercept demonstrated a significant reduction in tumor volume starting from day 10 after tumor inoculation (Figure 2A). We then evaluated the effects of systemic TNF ablation on MDSC accumulation by treating mice with etanercept (Figures 2B,C) and compared MDSC levels in the blood of tumor-bearing and tumor-free 
mice. As expected, mice under etanercept therapy accumulated significantly less MDSCs in the blood compared to mice under infliximab or PBS treatment, whereas tumor-free mice had very low MDSC levels (Figure 2B and data not shown). Moreover, we observed differences in MDSC levels starting from day 10, when the differences in tumor growth were also significant. Taken together, these data show that TNF neutralization might reduce tumor growth and MDSC accumulation in a transplantable MCA tumor model in mice.

\section{Treatment with Infliximab or Etanercept Efficiently Reduces Tumor Growth and MDSC Accumulation in Humanized TNF KI Mice}

One important difference between etanercept and antibody-based anti-TNF drugs (such as infliximab, adalimumab, and others) is that the former may also bind and neutralize soluble $\mathrm{LT}_{3}(45)$. Because several non-redundant functions of $s L T \alpha_{3}$ were reported, for instance, the role of $\mathrm{LT}_{3}$ produced by innate lymphoid cells in the gut (46), we wanted to make sure that the effects of etanercept in our tumor model (including results presented in Figure 2) were due to neutralization of TNF and not to soluble $\mathrm{LT}_{3}$. To this end, we compared the effects of anti-TNF therapy on tumor growth using humanized knock-in mice, which produce human TNF instead of murine TNF (further referred to as hTNF KI mice) (41, 42). This model allowed us to compare therapeutical effects of various human TNF blockers in vivo, in our case - etanercept and infliximab. First of all, tumor growth (Figures $2 \mathbf{A}$ and $\mathbf{3 A}$ ) and the accumulation of MDSCs (Figures $\mathbf{2 B}$ and $\mathbf{3 B}$ ) in tumor-bearing hTNF KI mice were comparable to those in wild-type mice, in both cases MDSCs reached $30-40 \%$ in the blood 3 weeks after MCA 205 tumor cells inoculation. We then compared the effects of TNF blockade with either etanercept or infliximab on MCA 205 growth and found that both drugs efficiently and comparably inhibited tumor growth (Figure 3A), indicating that anti-tumor effects were most likely due to TNF and not to sLTa neutralization. Three weeks after inoculation, the tumor volume in mice undergoing anti-TNF treatment reached only $200 \mathrm{~mm}^{3}$, as compared to $500-600 \mathrm{~mm}^{3}$ in the control group. Histological analysis revealed infiltration of the tumor tissue by myeloid cells in all three experimental groups (Figure S3 in Supplementary Material). We also observed a significant reduction in MDSC levels in the blood of mice treated with either of the two blockers (Figure 3B).

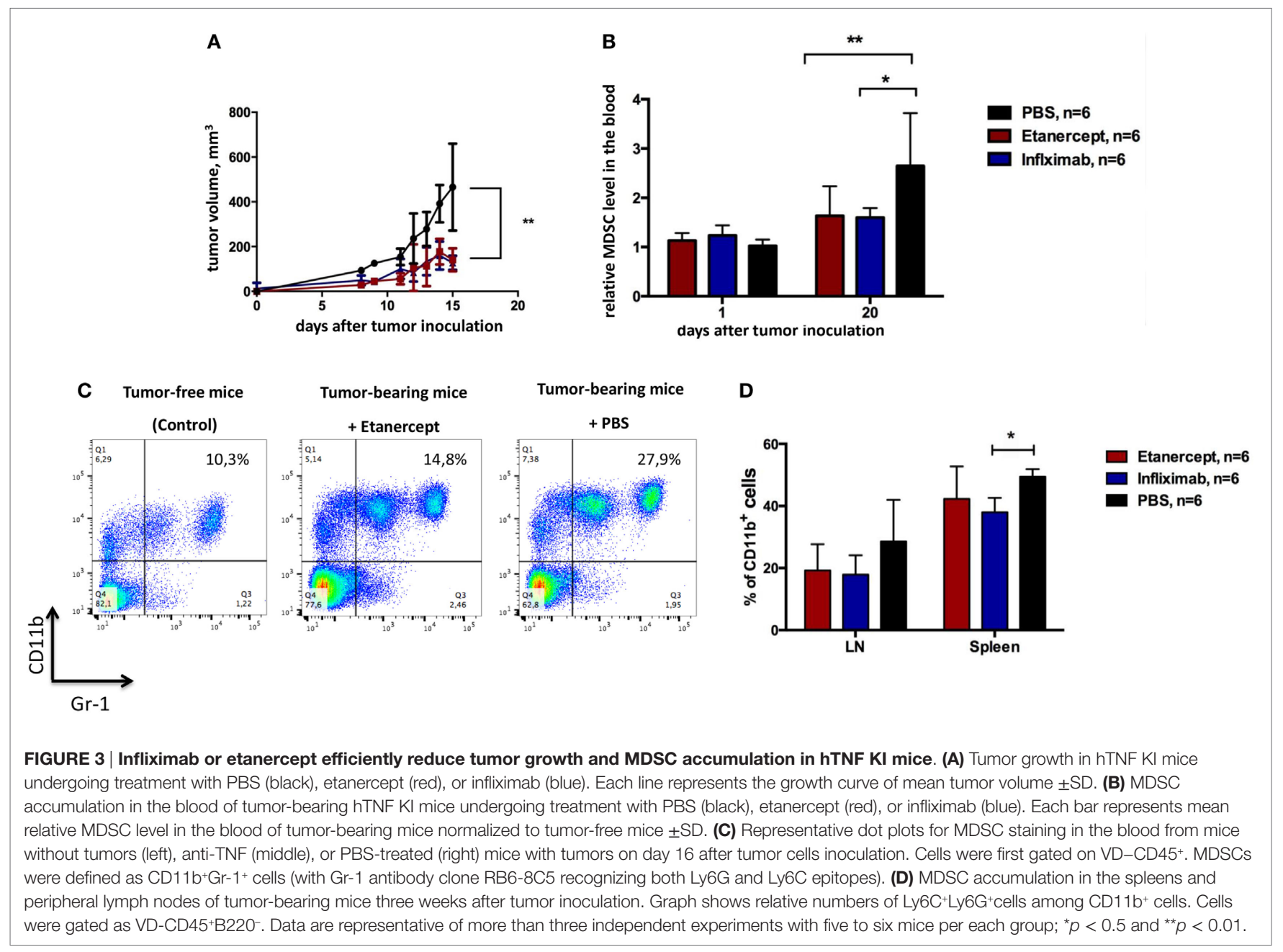


MDSC accumulation in control mice reached $30-40 \%$ of total leukocytes in the blood, while in mice treated with etanercept or infliximab it only reached $15-20 \%$ (Figure 3C). Tumor-free mice in each group, despite receiving TNF blockers, showed the same frequency of $\mathrm{CD} 11 \mathrm{~b}^{+} \mathrm{Gr}-1^{+}$myeloid cells, at approximately $8-10 \%$ of total blood leukocytes (Figure 3C). We also followed accumulation of MDSCs in the periphery: in lymph nodes and in the spleen, and found that the frequency of MDSCs was higher in PBS-treated group (Figure 3D). These data indicated that TNF plays a crucial role in MCA205 tumor growth and MDSC accumulation.

\section{Systemic TNF Inhibition Affects Suppressive Functions of MDSCs}

To study the impact of systemic TNF ablation on the functional properties of MDSCs, we examined ROS and NO production in vivo by blood MDSCs of tumor-bearing hTNF KI mice undergoing treatment with TNF inhibitors. We detected a significant reduction in $\mathrm{NO}$ in $\mathrm{CD}_{11} \mathrm{~b}^{+} \mathrm{Ly} 6 \mathrm{C}^{+}$myeloid cells in the blood of both etanercept- and infliximab-treated mice as compared to PBS-treated hTNF KI tumor-bearing mice (Figure 4A), whereas significant difference in ROS production was only detected in etanercept-treated tumor-bearing hTNF KI mice (Figure S2B in Supplementary Material). Furthermore, to address possible impact of anti-TNF treatment on MDSC functions, we evaluated suppressive activity of myeloid cells on T-cell proliferation using a co-culture of CFSE-labeled T-cells and purified MDSCs in the presence of agonistic anti-CD3 and anti-CD28 antibodies. MDSCs were isolated from the spleens of hTNF KI tumor-bearing mice undergoing treatment with antiTNF blockers or with PBS, as control. After 3 days of co-culture, we determined the label distribution in the population of $\mathrm{CD}^{+}$ T-cells (Figure 4B). As expected, purified MDSCs isolated from PBS-treated tumor-bearing mice completely suppressed T-cell proliferation (Figures 4B,E, left). Strikingly, MDSCs isolated from tumor-bearing mice under infliximab or etanercept treatment were not able to prevent $\mathrm{T}$-cell proliferation indicating that their suppressive function was compromised (Figures 4B,E, middle and right). Unstimulated and stimulated T-cells in the absence of MDSCs are shown as control stainings in Figures 4C,D). We also analyzed gene expression and evaluated their suppressive activity ex vivo. For this, we isolated MDSCs from the spleens of wild-type tumor-bearing mice after etanercept administration using magnetic bead separation (Figure S4A in Supplementary Material). We then performed gene expression analysis to see how anti-TNF treatment may affect the transcriptome of MDSCs (Figure S4B in Supplementary Material). We specifically looked for genes that encoded factors known to play an important role in MDSC function and found that at least some of them were indeed affected by systemic anti-TNF treatment. In particular, we observed significant reduction in the expression of il10, adam 17, and $t g f b$, while the expression of arginase- 1 gene was increased (Figure S4B in Supplementary Material). Taken together, our data demonstrated that systemic TNF inhibitors may not only reduce MDSC numbers but also affect their suppressive function.

\section{DISCUSSION}

Tumor microenvironment plays an important role in tumor growth and in resistance to therapies, in particular, through suppression of anti-tumor immune responses and by promoting angiogenesis, metastasis, and survival of cancer cells (47). Although certain mechanisms governing cross talk between microenvironment and tumor cells have been previously elucidated, the role of pro-inflammatory cytokines, such as TNF, IL-6, and IL-1, is not completely understood $(48,49)$. MDSCs represent a component of tumor microenvironment, which provides suppressive effects on immune cells, such as cytotoxic T-cells and NK-cells (23). Recently, it was shown that TNF is important for MDSC survival, expansion, and function $(32,33,35)$. Role of TNF is particularly interesting because TNF, as its name suggests, has a necrotizing anti-tumor activity in MCA sarcoma model in mice (25) that was reproduced with recombinant human TNF (50) and also because these anti-sarcoma effects are used clinically in the isolated limb perfusion setting (51). However, in other experimental models in mice and also in patients, TNF was reported to play a pro-tumorigenic role, and thus its therapeutic blockade may prove beneficial $(40,52)$. In our study, we demonstrated that systemic pharmacologic TNF ablation leads to the delay in transplantable tumor growth of MCA 205 fibrosarcoma, accompanied by decreased accumulation of MDSCs.

The reasons for these contrasting effects of endogenous versus systemically administered TNF are not fully understood. It is known that hemorrhagic necrosis of tumors is not due to direct TNF cytotoxicity on tumor cells but rather due to acute effects on tumor vasculature that is a part of tumor microenvironment (53) (Figure 5A). It is generally believed that such acute activating effects of TNF are very fast and are mediated by TNFRI. On the other hand, local effects of endogenous TNF, released from tumor cells and from tumor microenvironment, may be local and long-lasting and they could be mediated by both TNF receptors, with TNF-TNFRII axis having a distinct role because it requires tmTNF and cell-to-cell contacts (54). The downstream effects of such signaling may lead to the expression of proinflammatory cytokines, chemokines, and adhesion molecules resulting in chronic inflammation - one of the hallmarks of cancer development (55) (Figure 5B). In addition to this, TNF promotes expansion of MDSCs, which have pro-tumorigenic role and also accumulate during chronic inflammation $(32,33,35)$ (Figure 5C). As already discussed, TNF therapy has found only limited clinical application in cancer treatment, while anti-TNF therapy is widely used in the treatment of autoimmune diseases. Could such systemic and often long-term TNF blockade predispose autoimmune patients to cancer? Or on the contrary, could anti-cytokine therapy provide a protection against emerging tumors? These are types of questions that we want to address in animal models.

In order to compare possible in vivo anti-tumor effects of TNF blockers used in clinic, we utilized an experimental model of humanized (hTNF KI) mice, endogenously producing human but not mouse TNF $(41,42)$. We found that after injection of tumor cells, hTNF KI mice develop MCA 205-derived tumors comparably with $\mathrm{C} 57 \mathrm{Bl} / 6$ mice. TNF neutralization by either of the two 

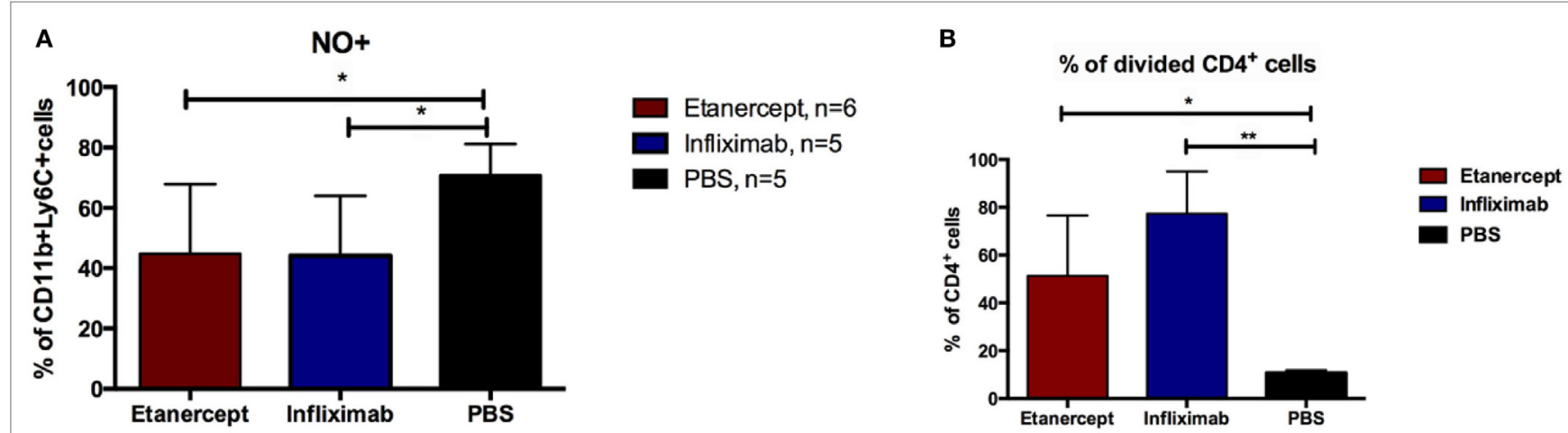

\section{Stimulated T-cells (anti-CD3, anti-CD28)}

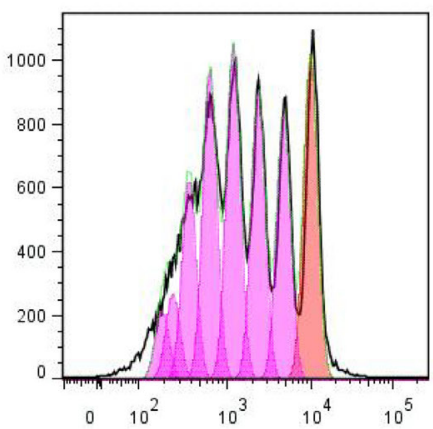

D Unstimulated T-cells (Control)

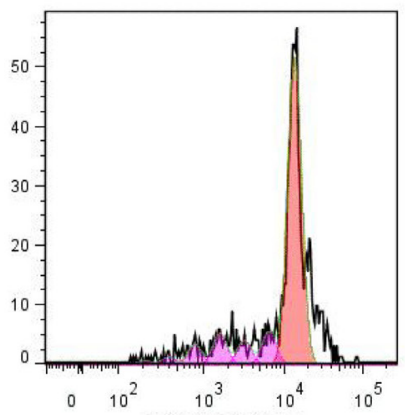

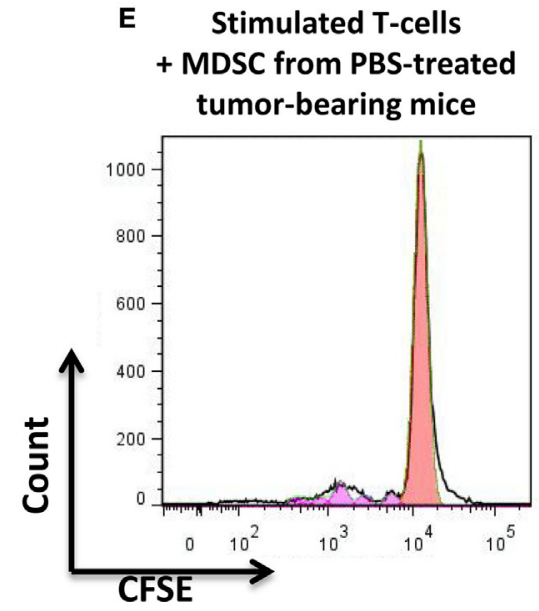

\section{Stimulated T-cells + MDSC from Etanercept-treated tumor-bearing mice}

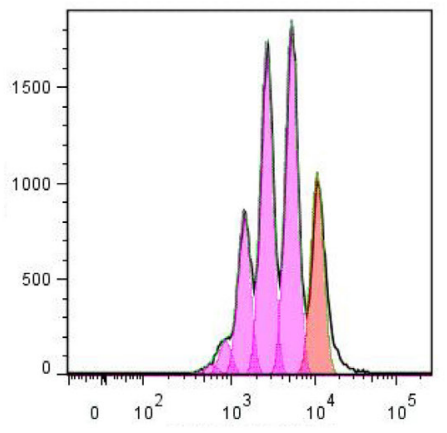

Stimulated T-cells

+ MDSC from Infliximab-treated tumor-bearing mice

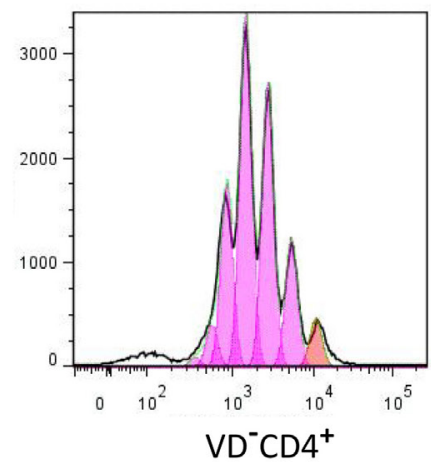

FIGURE 4 | Infliximab or etanercept efficiently inhibit suppressive functions of MDSCs. (A) Blood MDSCs of tumor-bearing hTNF KI mice undergoing treatment with etanercept (red) or infliximab (blue) have reduced levels of NO compared to PBS-treated mice (black). Data are representative of two independent experiments. (B) Purified splenic MDSCs from tumor-bearing hTNF KI mice undergoing systemic TNF ablation with etanercept (red) or infliximab (blue) fail to suppress T-cell proliferation. MDSCs and T-cells were co-cultured at ratio 5:1, $2 \times 10^{6}$ and $4 \times 10^{5}$ cells, respectively. (C) In vitro proliferation of purified CFSElabeled T-cells from the spleens of naive mice after three days of stimulation with anti-CD3 and anti-CD28 antibodies or (D) unstimulated T-cells. (E) CFSE-labeled T-cells from naive mice after three days of stimulation with anti-CD3 and anti-CD28 antibodies in the presence of purified splenic MDSCs from tumor-bearing mice treated with PBS (left), etanercept (middle), or infliximab (right). Pink and red peaks were defined as non-proliferating and proliferating cells, respectively. Cells were gated as $\mathrm{VD}^{-} \mathrm{CD}_{4}^{+}$. Data are representative of three independent experiments with each group represented by six mice, and MDSCs were isolated from pooled splenocytes from two to three mice. ${ }^{*} p<0.5$ and ${ }^{* *} p<0.01$.

blockers, infliximab or etanercept, resulted in comparable reduction of tumor volume in hTNF KI mice and also correlated with reduced frequency of MDSCs, which may play a pro-tumorigenic role (Figure 5D). This clearly suggests that the effects of etanercept administration are due to TNF and unlikely due to soluble $\mathrm{LT} \alpha_{3}$ blockade. This is an important observation, since the role 


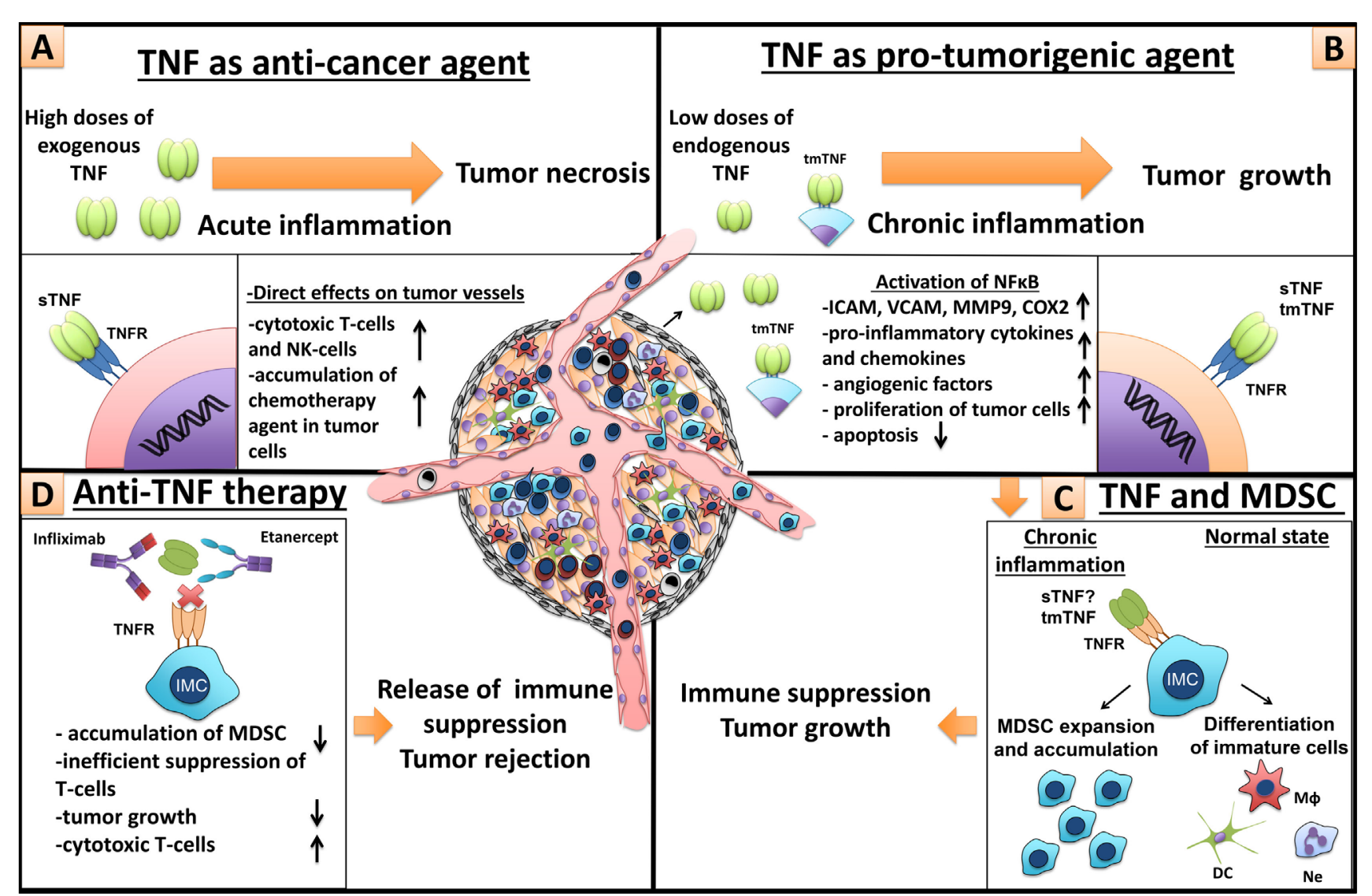

FIGURE 5 | Dual role of TNF in cancer and MDSCs. (A) TNF as anti-cancer agent. High doses of exogenous TNF induce tumor necrosis (25). However, necrotizing effect of TNF is not due to cytotoxic killing of tumor cells but because of direct action of TNF on endothelial cells, which leads to significant destruction of tumor-associated vessels and tumor rejection (56). Furthermore, TNF is an important molecule for anti-tumor immunity by cytotoxic NK- and T-cells (57, 58). In patients, TNF alone is inefficient, but in combination with chemotherapy, it increases tissue concentration of chemotherapy drugs, through the increase of blood vessel permeability, and is used in isolated perfusion procedure for the sarcoma treatment of the limb (59). (B) TNF as a pro-tumorigenic molecule. Binding of TNF with TNFR on endothelial cells and cancer-associated fibroblasts leads to NFKB activation and upregulation of chemokines, adhesion molecules, growth factors, and pro-inflammatory cytokines, resulting in increased angiogenesis, inflammation, and recruitment of immune cells (60, 61). TNF through the same signals activates proliferation of tumor cells and induces the release of different factors by tumor cells, such as metalloproteinases and VEGF, resulting in angiogenesis and tumor niche remodeling (62). (C) TNF and MDSCs. TNF and other pro-inflammatory cytokines, produced by tumor cells and tumor microenvironment, sustain chronic inflammation (63). During chronic inflammation myeloid cells do not differentiate into mature macrophages, neutrophils, and dendritic cells but rather accumulate as immature cells with suppressive capacity, so-called MDSCs (1). TNF is crucial for MDSCs, due to its direct effects on myeloid cells (33-35). MDSCs suppress anti-tumor immunity driving tumor development (9). (D) Anti-TNF therapy. Neutralization of TNF by etanercept or infliximab may result in tumor delay, decrease of MDSC accumulation, inefficient T-cell suppression, and increase of cytotoxic T-cells.

of lymphotoxin in carcinogenesis has been previously described (64-68). Furthermore, our experiments suggest that TNF inhibition affects MDSCs by altering their gene expression. Specifically, purified $\mathrm{CD} 11 \mathrm{~b}^{+} \mathrm{Gr}-1^{+}$cells, isolated from $\mathrm{C} 57 \mathrm{Bl} / 6$ mice undergoing etanercept treatment, showed decreased expression levels of genes that encode anti-inflammatory cytokine, such as TGF- $\beta$ and IL-10, which are necessary for polarization of M2 macrophages (69), differentiation of Tregs, capable of functional inhibition of cytotoxic cells (20-22). Specifically, we detected a reduced expression of the gene encoding ADAM17, which may cleave off CD62L from the surface of T-cells, providing MDSCs with the ability to prevent activation of naive T-cells by blocking their migration to the sites of inflammation (70). The same protease converts membrane-bound forms of pro-inflammatory cytokines and their receptors, such as IL-6R and TNF, into secreted soluble forms (71). Interestingly, in MDSCs from mice receiving antiTNF treatment, we detected an increase in the expression level of arginase-1 gene. This enzyme facilitates suppressive activity of MDSCs through degradation of arginine (14). Thus, these changes in gene expression could affect the function of myeloid cells and may be important for anti-tumor immunity. To address the question of how TNF blockade could affect suppressive capacity of MDSCs, we looked at ROS and NO production by blood MDSCs in vivo and also tested the ability of MDSCs to inhibit proliferation of T-cells in a functional assay ex vivo. We found that purified splenic MDSCs from hTNF KI tumor-bearing mice, undergoing infliximab or etanercept treatment, failed to suppress T-cell proliferation, whereas MDSCs from the control PBS-treated 
tumor-bearing mice had the expected suppressive activity. This supports our in vivo data concerning significantly reduced level of NO in blood MDSCs of mice receiving either etanercept or infliximab. These findings imply that TNF inhibition not only reduces accumulation of MDSCs but also affects their suppressive capacity. Overall, our data support the notion that MDSCs may be a target for anti-tumor therapy in patients and it also highlights TNF as a mediator with non-redundant pro-tumorigenic functions. One possible avenue in anti-cytokine therapy being developed in our laboratory is to neutralize pro-inflammatory cytokines in cell-restricted fashion (41). For using such a strategy in cancer treatment, cellular sources of pro-tumorigenic cytokine in each particular case should be first identified.

\section{AUTHOR CONTRIBUTIONS}

$\mathrm{MD}, \mathrm{K}-\mathrm{SA}$, and SN designed the research; ZQ contributed to the new experimental approach; K-SA, VG, MN, RZ, and MD performed the experiments; K-SA and MN analyzed the data;

\section{REFERENCES}

1. Ostrand-Rosenberg S, Sinha P. Myeloid-derived suppressor cells: linking inflammation and cancer. J Immunol (2009) 182:4499-506. doi:10.4049/ jimmunol.0802740

2. Youn J-I, Nagaraj S, Collazo M, Gabrilovich DI. Subsets of myeloid-derived suppressor cells in tumor bearing mice. J Immunol (2008) 181:5791-802. doi:10.4049/jimmunol.181.8.5791

3. Almand B, Clark JI, Nikitina E, Van Beynen J, English NR, Knight SC, et al. Increased production of immature myeloid cells in cancer patients: a mechanism of immunosuppression in cancer. J Immunol (2001) 166:678-89. doi:10.4049/jimmunol.166.1.678

4. Ochoa AC, Zea AH, Hernandez C, Rodriguez PC. Arginase, prostaglandins, and myeloid-derived suppressor cells in renal cell carcinoma. Clin Cancer Res (2007) 13:721s-6s. doi:10.1158/1078-0432.CCR-06-2197

5. Donkor MK, Lahue E, Hoke TA, Shafer LR, Coskun U, Solheim JC, et al. Mammary tumor heterogeneity in the expansion of myeloid-derived suppressor cells. Int Immunopharmacol (2009) 9:937-48. doi:10.1016/j. intimp.2009.03.021

6. Centuori SM, Trad M, Lacasse CJ, Alizadeh D, Larmonier CB, Hanke NT, et al. Myeloid-derived suppressor cells from tumor-bearing mice impair TGF-beta-induced differentiation of CD4+CD25+FoxP3+ Tregs from CD4+CD25-FoxP3-T cells. J Leukoc Biol (2012) 92:987-97. doi:10.1189/ jlb.0911465

7. Younos IH, Dafferner AJ, Gulen D, Britton HC, Talmadge JE. Tumor regulation of myeloid-derived suppressor cell proliferation and trafficking. Int Immunopharmacol (2012) 13:245-56. doi:10.1016/j.intimp.2012.05.002

8. Wang L, Chang EW, Wong SC, Ong SM, Chong DQ, Ling KL. Increased myeloid-derived suppressor cells in gastric cancer correlate with cancer stage and plasma S100A8/A9 proinflammatory proteins. J Immunol (2013) 190:794-804. doi:10.4049/jimmunol.1202088

9. Gabrilovich DI, Ostrand-Rosenberg S, Bronte V. Coordinated regulation of myeloid cells by tumours. Nat Rev Immunol (2012) 12:253-68. doi:10.1038/ nri3175

10. Cheng P, Corzo CA, Luetteke N, Yu B, Nagaraj S, Bui MM, et al. Inhibition of dendritic cell differentiation and accumulation of myeloid-derived suppressor cells in cancer is regulated by S100A9 protein. J Exp Med (2008) 205:2235-49. doi:10.1084/jem.20080132

11. Sinha P, Okoro C, Foell D, Freeze HH, Ostrand-Rosenberg S, Srikrishna G. Proinflammatory S100 proteins regulate the accumulation of myeloidderived suppressor cells. J Immunol (2008) 181:4666-75. doi:10.4049/ jimmunol.181.7.4666
$\mathrm{K}-\mathrm{SA}, \mathrm{MN}, \mathrm{MD}, \mathrm{ZQ}$, and $\mathrm{SN}$ discussed the data; and $\mathrm{K}-\mathrm{SA}, \mathrm{MD}$, and $\mathrm{SN}$ wrote the paper.

\section{ACKNOWLEDGMENTS}

We thank Drs. G. A. Efimov, A. A. Kruglov, E. S. Shilov, and Prof. T. Blankenstein for their advice and providing important research materials. This work was supported by the Russian Science Foundation grant 14-25-00160 (flow cytometry and gene expression analysis, Figures 2B,C, 3B-D, 4 and 5; Figures S1-S3 in Supplementary Material), RFBR grant 14-04-91186 (anti-cytokine therapy and tumor transplantation experiments, Figures 1, 2A and 3A; Figure S4 in Supplementary Material), and National Natural Science Foundation of China grant 81411130218 (ZQ).

\section{SUPPLEMENTARY MATERIAL}

The Supplementary Material for this article can be found online at http://journal.frontiersin.org/article/10.3389/fimmu.2016.00147

12. Botta C, Gullà A, Correale P, Tagliaferri P, Tassone P. Myeloid-derived suppressor cells in multiple myeloma: pre-clinical research and translational opportunities. Front Oncol (2014) 4:348. doi:10.3389/fonc.2014.00348

13. Mazzoni A, Bronte V, Visintin A, Spitzer JH, Apolloni E, Serafini P, et al. Myeloid suppressor lines inhibit $\mathrm{T}$ cell responses by an NO-dependent mechanism. J Immunol (2002) 168:689-95. doi:10.4049/jimmunol.168.2.689

14. Rodriguez PC, Quiceno DG, Ochoa AC. L-Arginine availability regulates T-lymphocyte cell-cycle progression. Blood (2007) 109:1568-73. doi:10.1182/ blood-2006-06-031856

15. Martino A, Badell E, Abadie V, Balloy V, Chignard M, Mistou M-Y, et al. Mycobacterium bovis bacillus Calmette-Guérin vaccination mobilizes innate myeloid-derived suppressor cells restraining in vivo $\mathrm{T}$ cell priming via IL-1R-dependent nitric oxide production. J Immunol (2010) 184:2038-47. doi:10.4049/jimmunol.0903348

16. Diefenbach A, Jensen ER, Jamieson AM, Raulet DH. Rae1 and H60 ligands of the NKG2D receptor stimulate tumor immunity. Nature (2001) 413:165-71. doi:10.1038/35093109

17. Schmielau J, Finn OJ. Activated granulocytes and granulocyte-derived hydrogen peroxide are the underlying mechanism of suppression of T-cell function in advanced cancer patients. Cancer Res (2001) 61:4756-60.

18. Hoechst B, Voigtlaender T, Ormandy L, Gamrekelashvili J, Zhao F, Wedemeyer $\mathrm{H}$, et al. Myeloid derived suppressor cells inhibit natural killer cells in patients with hepatocellular carcinoma via the NKp30 receptor. Hepatology (2009) 50:799-807. doi:10.1002/hep.23054

19. Li H, Han Y, Guo Q, Zhang M, Cao X. Cancer-expanded myeloid-derived suppressor cells induce anergy of NK cells through membrane-bound TGFB1. J Immunol (2009) 182:240-9. doi:10.4049/jimmunol.182.1.240

20. Guiducci C, Valzasina B, Dislich H, Colombo MP. CD40/CD40L interaction regulates $\mathrm{CD} 4+\mathrm{CD} 25+\mathrm{T}$ reg homeostasis through dendritic cell-produced IL-2. Eur J Immunol (2005) 35:557-67. doi:10.1002/eji.200425810

21. Huang B, Pan PY, Li Q, Sato AI, Levy DE, Bromberg J, et al. Gr-1+CD115+ immature myeloid suppressor cells mediate the development of tumorinduced $\mathrm{T}$ regulatory cells and T-cell anergy in tumor-bearing host. Cancer Res (2006) 66:1123-31. doi:10.1158/0008-5472.CAN-05-1299

22. Pan PY, Ma G, Weber KJ, Ozao-Choy J, Wang G, Yin B, et al. Immune stimulatory receptor CD40 is required for T-cell suppression and T regulatory cell activation mediated by myeloid-derived suppressor cells in cancer. Cancer Res (2010) 70:99-108. doi:10.1158/0008-5472.CAN-09-1882

23. Parker KH, Beury DW, Ostrand-Rosenberg S. Myeloid-derived suppressor cells: critical cells driving immune suppression in the tumor microenvironment. Adv Cancer Res (2015) 128:95-139. doi:10.1016/ bs.acr.2015.04.002 
24. Drutskaya MS, Efimov GA, Kruglov AA, Kuprash DV, Nedospasov SA. Tumor necrosis factor, lymphotoxin and cancer. IUBMB Life (2010) 62:283-9. doi:10.1002/iub.309

25. Carswell EA, Old LJ, Kassel RL, Green S, Fiore N, Williamson B. An endotoxin-induced serum factor that causes necrosis of tumors. Proc Natl Acad Sci U $S$ A (1975) 72:3666-70. doi:10.1073/pnas.72.9.3666

26. Pereira R, Lago P, Faria R, Torres T. Safety of anti-TNF therapies in immunemediated inflammatory diseases: focus on infections and malignancy. Drug Dev Res (2015) 76(8):419-27. doi:10.1002/ddr.21285

27. Moore RJ, Owens DM, Stamp G, Arnott C, Burke F, East N, et al. Mice deficient in tumor necrosis factor-alpha are resistant to skin carcinogenesis. Nat Med (1999) 5:828-31. doi:10.1038/10462

28. Pikarsky E, Porat RM, Stein I, Abramovitch R, Amit S, Kasem S, et al. NF-kappaB functions as a tumour promoter in inflammation-associated cancer. Nature (2004) 431:461-6. doi:10.1038/nature02924

29. Kulbe H, Thompson R, Wilson JL, Robinson S, Hagemann T, Fatah R, et al. The inflammatory cytokine tumor necrosis factor-alpha generates an autocrine tumor-promoting network in epithelial ovarian cancer cells. Cancer Res (2007) 67:585-92. doi:10.1158/0008-5472.CAN-06-2941

30. Popivanova BK, Kitamura K, Wu Y, Kondo T, Kagaya T, Kaneko S, et al. Blocking TNF-alpha in mice reduces colorectal carcinogenesis associated with chronic colitis. J Clin Invest (2008) 118:560-70. doi:10.1172/JCI32453

31. Bauer J, Namineni S, Reisinger F, Zoller J, Yuan D, Heikenwalder M. Lymphotoxin, NF-kB, and cancer: the dark side of cytokines. Dig Dis (2012) 30:453-68. doi:10.1159/000341690

32. Zhao X, Rong L, Zhao X, Li X, Liu X, Deng J, et al. TNF signaling drives myeloid-derived suppressor cell accumulation. J Clin Invest (2012) 122:4094104. doi:10.1172/JCI64115

33. Hu X, Li B, Li X, Zhao X, Wan L, Lin G, et al. Transmembrane TNF-alpha promotes suppressive activities of myeloid-derived suppressor cells via TNFR2. J Immunol (2014) 192:1320-31. doi:10.4049/jimmunol.1203195

34. Polz J, Remke A, Weber S, Schmidt D, Weber-Steffens D, Pietryga-Krieger A, et al. Myeloid suppressor cells require membrane TNFR2 expression for suppressive activity. Immun Inflamm Dis (2014) 2:121-30. doi:10.1002/iid3.19

35. Sade-Feldman M, Kanterman J, Ish-Shalom E, Elnekave M, Horwitz E, Baniyash M. Tumor necrosis factor-alpha blocks differentiation and enhances suppressive activity of immature myeloid cells during chronic inflammation. Immunity (2013) 38:541-54. doi:10.1016/j.immuni.2013.02.007

36. Joyce JA, Pollard JW. Microenvironmental regulation of metastasis. Nat Rev Cancer (2009) 9:239-52. doi:10.1038/nrc2618

37. Oh K, Lee OY, Shon SY, Nam O, Ryu PM, Seo MW, et al. A mutual activation loop between breast cancer cells and myeloid-derived suppressor cells facilitates spontaneous metastasis through IL-6 trans-signaling in a murine model. Breast Cancer Res (2013) 15:R79. doi:10.1186/bcr3473

38. Chen MF, Kuan FC, Yen TC, Lu MS, Lin PY, Chung YH, et al. IL-6-stimulated CD11b+ CD14+ HLA-DR-myeloid-derived suppressor cells, are associated with progression and poor prognosis in squamous cell carcinoma of the esophagus. Oncotarget (2014) 5:8716-28. doi:10.18632/oncotarget.2368

39. Astrakhantseva IV, Efimov GA, Drutskaya MS, Kruglov AA, Nedospasov SA. Modern anti-cytokine therapy of autoimmune diseases. Biochemistry (Mosc) (2014) 79:1308-21. doi:10.1134/S0006297914120049

40. Anderson GM, Nakada MT, Dewitte M. Tumor necrosis factor-alpha in the pathogenesis and treatment of cancer. Curr Opin Pharmacol (2004) 4:314-20. doi:10.1016/j.coph.2004.04.004

41. Efimov GA, Kruglov AA, Khlopchatnikova ZV, Rozov FN, Mokhonov VV, Rose-John S, et al. Cell-type-restricted anti-cytokine therapy: TNF inhibition from one pathogenic source. Proc Natl Acad Sci U S A (2016) 113:3006-11. doi:10.1073/pnas.1520175113

42. Olleros ML, Chavez-Galan L, Segueni N, Bourigault ML, Vesin D, Kruglov AA, et al. Control of mycobacterial infections in mice expressing human tumor necrosis factor (TNF) but not mouse TNF. Infect Immun (2015) 83:3612-23. doi:10.1128/IAI.00743-15

43. Childs LM, Goater JJ, O’Keefe RJ, Schwarz EM. Efficacy of etanercept for wear debris-induced osteolysis. J Bone Miner Res (2001) 16:338-47. doi:10.1359/ jbmr.2001.16.2.338

44. Mikuls TR, Moreland LW. TNF blockade in the treatment of rheumatoid arthritis: infliximab versus etanercept. Expert Opin Pharmacother (2001) 2:75-84. doi:10.1517/14656566.2.1.75
45. Furst DE, Wallis R, Broder M, Beenhouwer DO. Tumor necrosis factor antagonists: different kinetics and/or mechanisms of action may explain differences in the risk for developing granulomatous infection. Semin Arthritis Rheum (2006) 36:159-67. doi:10.1016/j.semarthrit.2006.02.001

46. Kruglov AA, Grivennikov SI, Kuprash DV, Winsauer C, Prepens S, Seleznik GM, et al. Nonredundant function of soluble LTalpha3 produced by innate lymphoid cells in intestinal homeostasis. Science (2013) 342:1243-6. doi:10.1126/science.1243364

47. Balkwill FR, Capasso M, Hagemann T. The tumor microenvironment at a glance. J Cell Sci (2012) 125:5591-6. doi:10.1242/jcs.116392

48. Apte RN, Voronov E. Is interleukin-1 a good or bad 'guy' in tumor immunobiology and immunotherapy? Immunol Rev (2008) 222:222-41. doi:10.1111/j.1600-065X.2008.00615.X

49. Landskron G, De La Fuente M, Thuwajit P, Thuwajit C, Hermoso MA. Chronic inflammation and cytokines in the tumor microenvironment. J Immunol Res (2014) 2014:149185. doi:10.1155/2014/149185

50. Asher A, Mule JJ, Reichert CM, Shiloni E, Rosenberg SA. Studies on the anti-tumor efficacy of systemically administered recombinant tumor necrosis factor against several murine tumors in vivo. J Immunol (1987) 138:963-74.

51. Hill S, Fawcett WJ, Sheldon J, Soni N, Williams T, Thomas JM. Low-dose tumour necrosis factor alpha and melphalan in hyperthermic isolated limb perfusion. Br J Surg (1993) 80:995-7. doi:10.1002/bjs.1800800820

52. Balkwill F. TNF-alpha in promotion and progression of cancer. Cancer Metastasis Rev (2006) 25:409-16. doi:10.1007/s10555-006-9005-3

53. Havell EA, Fiers W, North RJ. The antitumor function of tumor necrosis factor (TNF), I. Therapeutic action of TNF against an established murine sarcoma is indirect, immunologically dependent, and limited by severe toxicity. J Exp Med (1988) 167:1067-85. doi:10.1084/jem.167.3.1067

54. Arnott CH, Scott KA, Moore RJ, Robinson SC, Thompson RG, Balkwill FR. Expression of both TNF-alpha receptor subtypes is essential for optimal skin tumour development. Oncogene (2004) 23:1902-10. doi:10.1038/ sj.onc. 1207317

55. Hanahan D, Weinberg RA. Hallmarks of cancer: the next generation. Cell (2011) 144:646-74. doi:10.1016/j.cell.2011.02.013

56. Stoelcker B, Ruhland B, Hehlgans T, Bluethmann H, Luther T, Mannel DN. Tumor necrosis factor induces tumor necrosis via tumor necrosis factor receptor type 1-expressing endothelial cells of the tumor vasculature. Am J Pathol (2000) 156:1171-6. doi:10.1016/S0002-9440(10)64986-3

57. Kashii Y, Giorda R, Herberman RB, Whiteside TL, Vujanovic NL. Constitutive expression and role of the TNF family ligands in apoptotic killing of tumor cells by human NK cells. J Immunol (1999) 163:5358-66.

58. Prevost-Blondel A, Roth E, Rosenthal FM, Pircher H. Crucial role of TNF-alpha in CD8 T cell-mediated elimination of 3LL-A9 Lewis lung carcinoma cells in vivo. J Immunol (2000) 164:3645-51. doi:10.4049/jimmunol.164.7.3645

59. Grunhagen DJ, De Wilt JH, Graveland WJ, Verhoef C, Van Geel AN, Eggermont AM. Outcome and prognostic factor analysis of 217 consecutive isolated limb perfusions with tumor necrosis factor-alpha and melphalan for limb-threatening soft tissue sarcoma. Cancer (2006) 106:1776-84. doi:10.1002/cncr.21802

60. Mantovani A, Dejana E. Cytokines as communication signals between leukocytes and endothelial cells. Immunol Today (1989) 10:370-5. doi:10.1016/0167-5699(89)90270-3

61. Stuelten CH, Dacosta Byfield S, Arany PR, Karpova TS, Stetler-Stevenson WG, Roberts AB. Breast cancer cells induce stromal fibroblasts to express MMP-9 via secretion of TNF-alpha and TGF-beta. JCell Sci (2005) 118:2143-53. doi:10.1242/jcs.02334

62. Szlosarek P, Charles KA, Balkwill FR. Tumour necrosis factor-alpha as a tumour promoter. Eur J Cancer (2006) 42:745-50. doi:10.1016/j.ejca.2006.01.012

63. Colotta F, Allavena P, Sica A, Garlanda C, Mantovani A. Cancer-related inflammation, the seventh hallmark of cancer: links to genetic instability. Carcinogenesis (2009) 30:1073-81. doi:10.1093/carcin/bgp127

64. Hehlgans T, Stoelcker B, Stopfer P, Muller P, Cernaianu G, Guba M, et al. Lymphotoxin-beta receptor immune interaction promotes tumor growth by inducing angiogenesis. Cancer Res (2002) 62:4034-40.

65. Haybaeck J, Zeller N, Wolf MJ, Weber A, Wagner U, Kurrer MO, et al. A lymphotoxin-driven pathway to hepatocellular carcinoma. Cancer Cell (2009) 16:295-308. doi:10.1016/j.ccr.2009.08.021 
66. Zhou P, Fang X, Mcnally BA, Yu P, Zhu M, Fu YX, et al. Targeting lymphotoxin-mediated negative selection to prevent prostate cancer in mice with genetic predisposition. Proc Natl Acad Sci U S A (2009) 106:17134-9. doi:10.1073/pnas.0905707106

67. Ammirante M, Luo JL, Grivennikov S, Nedospasov S, Karin M. B-cell-derived lymphotoxin promotes castration-resistant prostate cancer. Nature (2010) 464:302-5. doi:10.1038/nature08782

68. Daller B, Musch W, Rohrl J, Tumanov AV, Nedospasov SA, Mannel DN, et al. Lymphotoxin-beta receptor activation by lymphotoxin-alpha(1)beta(2) and LIGHT promotes tumor growth in an NFkappaB-dependent manner. Int J Cancer (2011) 128:1363-70. doi:10.1002/ijc.25456

69. Schmieder A, Michel J, Schonhaar K, Goerdt S, Schledzewski K. Differentiation and gene expression profile of tumor-associated macrophages. Semin Cancer Biol (2012) 22:289-97. doi:10.1016/j. semcancer.2012.02.002

70. Hanson EM, Clements VK, Sinha P, Ilkovitch D, Ostrand-Rosenberg S. Myeloid-derived suppressor cells down-regulate L-selectin expression on CD4+ and CD8+ T cells. J Immunol (2009) 183:937-44. doi:10.4049/ jimmunol.0804253

71. Lisi S, D'Amore M, Sisto M. ADAM17 at the interface between inflammation and autoimmunity. Immunol Lett (2014) 162:159-69. doi:10.1016/j. imlet.2014.08.008

Conflict of Interest Statement: The authors declare that the research was conducted in the absence of any commercial or financial relationships that could be construed as a potential conflict of interest.

Copyright $\odot 2016$ Atretkhany, Nosenko, Gogoleva, Zvartsev, Qin, Nedospasov and Drutskaya. This is an open-access article distributed under the terms of the Creative Commons Attribution License (CC BY). The use, distribution or reproduction in other forums is permitted, provided the original author(s) or licensor are credited and that the original publication in this journal is cited, in accordance with accepted academic practice. No use, distribution or reproduction is permitted which does not comply with these terms. 